\title{
Open Access Publication: An Important Pathway for the Advancement of Science and Patient Care
}

\section{Cui Hua Liu*}

Associate Professor, CAS Key Laboratory of Pathogenic Microbiology and Immunology, Institute of O icrobiology, Chinese Academy of Sciences, China

Open Access (OA) is a distribution model providing no-cost, nowait, online access to academic works such as peer-reviewed journal articles, theses, monographs and book chapters [1,2], thus it is an important pathway to accelerate the pace of scientific progress and to improve patient care.

The benefits of the OA publication in the advancement of science and patient care have been shown in several aspects, such as: 1) it accelerates communication and thus discovery and innovation; 2) publishers benefit from the wider dissemination, greater visibility and impact of their articles; 3 ) scientists, clinicians, and the public benefit from an immediate open access option to published scientific and clinically relevant information [3-6]

The Journal of Pulmonary \& Respiratory Medicine, which started as a new OMICS Publishing Group journal in October 2011, represents an excellent example of an OA platform. It aims to advance our understanding of the diagnosis and treatment of lung diseases, as well as secondary prevention (Tuberculosis). It is an international, peer-reviewed journal, publishing an overview of pulmonary medicine which includes the contents geared towards the fields of pulmonology, thoracic surgery, and intensive care medicine. For more details: http:// www.omicsonline.org/jprmhome.php.

OMICS Publishing Group, an Open Access Publisher and Scientific Events Organizer for the Advancement of Science \& Technology, enables the dissemination of research articles to the global community by publishing about 200 journals (except for the above-mentioned Journal of Pulmonary \& Respiratory Medicine) and organizing 50 (on average) scientific events per year via OA model. The special features of the OMICS Publishing Group include: 1) providing digital book, which enables readers to listen to their research almost immediately; 2) supplying audio listening; 3 ) offering user friendly/feasible websitetranslation of published papers to more than 50 languages, which enables worldwide communication with researchers in a variety of languages; 4) enabling readers to share their views on their research or on OMICS articles in various social networking sites such as Face book; and 5) ensuring quality and quick editorial and review processing with the efforts of 5,000 editorial teams and 10,000 reviewer teams, and it owns 1 million readers. For more details: http://www.omicsonline.org/ special-features.php.

There are some opponents to OA model arguing that OA journals face many uncertainties such as quality, impact, and sustainability, and there are others who worry about the copyright issue raised by the $\mathrm{OA}$ model $[1,2,7]$. Despite these disputes, recent studies have revealed that the number of articles published in OA journals has grown quickly [3$6,8]$.

In summary, although many issues remain to be resolved for successful implementation of the OA publication model, the OA approach in medical research publication is proving to be successful and will continue to grow through constant efforts of scientific leaders and information professionals as well as the public as a whole $[9,10]$.

\section{References}

1. Lyons MG (2010) Open access is almost here: navigating through copyright, fair use, and the Teach act. J Contin Educ Nurs 41: 57-64.

2. Ammerman JW (2011) Open-Access to Nutrition Research Information: A Public Policy Debate. J Am Diet Assoc 111: 678-682.

3. Marcel Hommel (2010) 10 years of Malaria Journal: how did Open Access change publication patterns? Malar J 9: 284.

4. Giannella-Neto D, Gomes Mde B (2009) Diabetology \& Metabolic Syndrome: providing an open access future for diabetes research. Diabetol Metab Syndr 1: 1.

5. Lee J, Scott DJ, Villarroel M, Clifford GD, Saeed M, et al. (2011) Open-Access MIMIC-II Database for Intensive Care Research. Conf Proc IEEE Eng Med Biol Soc 2011: 8315-8318.

6. Kayser K (2011) Diagnostic Pathology in 2010: the successes and perspectives of open access publication. Diagn Pathol 6: 2 .

7. Lansingh VC, Carter MJ (2009) Does Open Access in Ophthalmology Affect How Articles Are Subsequently Cited in Research? Ophthalmology 116: 1425-1431.

8. Laakso M, Welling P, Bukvova H, Nyman L, Björk BC, et al. (2011) The Development of Open Access Journal Publishing from 1993 to 2009. PLoS ONE 6: 20961.

9. O'Dowd A (2011) Open access approach to medical research publishing will continue to grow, experts predict. BMJ 342: 3307.

10. Barbour V, Jones JC, Jones S, Norton M, Veitch E (2011) On the path to globa open access: a few more miles to go. PLoS Med 8: 1001014.
*Corresponding author: Dr. Cui Hua Liu, Associate Professor, CAS Key Laboratory of Pathogenic Microbiology and Immunology, Institute of 10 icrobiology, Chinese Academy of Sciences, Room A216, NO.8 North 2 Zhongguancun Road, Haidian District, Beijing 100190, China, Tel: 86-10-62554387; E-mail: liucuihua@im.ac.cn

Received March 05, 2012; Accepted March 08, 2012; Published March 10, 2012

Citation: Liu C (2012) Open Access Publication: An Important Pathway for the Advancement of Science and Patient Care. J Pulmonar Respirat Med 2:e106. doi:10.4172/2161-105X.1000e106

Copyright: () 2012 Liu C. This is an open-access article distributed under the terms of the Creative Commons Attribution License, which permits unrestricted use, distribution, and reproduction in any medium, provided the original author and source are credited. 